\title{
Study on Process Economics of Natural Resource Utilization
}

\author{
Wenfeng Hao ${ }^{1,2,3}$ \\ ${ }^{1}$ Department of Chemical Engineering for Energy, College of New Energy, Shenyang Institute of Engineering, Shenyang, China \\ ${ }^{2}$ Center for Natural Gas Hydrate Research, Guangzhou Institute of Energy Conversion, Chinese Academy of Sciences, Guangzhou, China \\ ${ }^{3}$ Institute of Adsorption and Inorganic Membrane, State Key Laboratory of Fine Chemicals, Dalian University of Technology, Dalian, \\ China
}

Email: haowenfeng@163.com

How to cite this paper: Hao, W.F. (2016) Study on Process Economics of Natural Resource Utilization. Natural Resources, 7, 611-627.

http://dx.doi.org/10.4236/nr.2016.711049

Received: July 25, 2016

Accepted: November 15, 2016

Published: November 18, 2016

Copyright $\odot 2016$ by author and Scientific Research Publishing Inc. This work is licensed under the Creative Commons Attribution International License (CC BY 4.0).

http://creativecommons.org/licenses/by/4.0/

\section{Abstract}

Finite supply of non-regenerative resources triggers a competition between economic entities or between areas, which requires the ways regarding their utilization with higher levels in science and the standards regarding their use with higher efficiency in economics. To solve a problem of process evaluation in science and of driving force in economics during a process design or a process run for natural resources utilization, a process evaluation parameter originated from natural gas hydrate preparation from a small scale to industrialization scale and the equation of the criterion dependent are introduced to evaluate a variety of processes of natural resources utilization. The analyses indicate that the parameter is relevant to internal undeveloped resources amount change with a stable mass composition in a virtual black box model and external variable market with an implication of process efficiency in economy or of process efficiency of resource utilization and that the parameter has similar features of the thermodynamic state functions. Moreover, the equation of the criterion provided is a difference between the value of the process evaluation parameter at the final state and the value of the process evaluation parameter at the initial state in an actual process, which can be used to determine the direction of development and to judge the size of the driving force in an actual process or an economical run. The provided examples and correlative mathematical description can guide how an identification for the undeveloped resources and a real-time adjustment of dynamic production for the developing resource are done and how decisions regarding resource exploitation, the venture forecasting of capital utilization and updating technology are made. The parameter used itself and the equation of the derived criterion can help by playing a predictive role for selecting the optimal use processes and for designing new process of the natural resource utilization or capital use, and by playing a practical role for adjusting factual production status and for improving the actual 
process of the utilization of resource or capital in an economic society. Finally, those closed resource systems having accumulation or depletion of the resources or a variable mass such as a decomposition system, a fission system and a biological reproduction system will become possible future research objectives under the guide of this work.

\section{Keywords}

Economics, Criterion, Natural Resources Utilization, Process Evaluation Parameter, Thermodynamics, Driving Force

\section{Introduction}

Twenty-first century is a vigorous century, new scientific discoveries and new production methods are emerging constantly. New concepts such as computer virtual resources platform, networking and three dimensional printing technology also have brought us new perspectives and new opportunities to our production and our livelihood in this buoyant century [1] [2]. However, while those new resources are created from a virtual world we still rely heavily on our conventional entities of natural resources, especially for our non-regenerative resources in our natural world although great progress has been made in science and technology. Because of their limited supply, non-regenerative resources have received significant attention continuously and continuously, the standards regarding their use and how they are used, which is directly linked to every aspect of the economy [3] [4] [5]. All of those associated issues determine directly whether the economy can maintain sustainable development [6] [7]. Therefore, a mean for scientific development or an effective way of a real-time adjustment should be adopted to exploit non-regenerative resources to maximize the efficiency of use and the economic value.

Generally natural resource exploitation occurs under the following circumstances: 1) an identification of developed technology for undeveloped resources and 2) a dynamic production real-time adjustment for developing resources under a certain developing technology.

To address the first issue, design and compare current schemes of scientific research, production schemes and monitoring schemes in current industry for each circumstance must be done. An appropriate project to implement various processes of natural resource utilization from these comparisons and analyses also must be selected. Comparative studies of Pete Parker et al. found that external capital input could alleviate the dependence for the local natural resources and that local natural surroundings could be protected effectively though there existed a good development way to those natural resource in modern society [8]. However, this is limited to some special conditions such as conservation area project. To maintain the sustainable development of economy, natural resource found still needs to be developed rationally and to be utilized efficiently. Data investigations of Yuasa K. et al. showed that district heating and cooling not only could decrease consumption by resource saving but also could play multiple 
roles for solving some problems such as energy conservation, urban disaster prevention, and global environment protection [9]. Comprehensive investigation of Ma Y.F. et al. showed that a lignite-fire power generation process based on boiler with an open pulverizing system had had higher levels in technical layers such as overall thermal efficiency, the water consumption and the pollutant emissions [10]. These mentioned samples indicated that conventional natural resources had had their own operational model in our modern society and that a decision on whether the natural resource should be exploited or on how the development objectives of the natural resource were should be made when the natural resource was being faced diversified development options. It requires that use ways of the natural resource must be optimized before natural resources can be implemented. However, so far there is not still an excellent state on what the uniform standards are to evaluate these operating processes in our market economy and on how the decisions should be done facing a variety of choices of the natural resources development in our market economy. Thus, process evaluation and optimal selection methods will be introduced in this work, which will advance the actualization of resource conserving efforts and environmentally friendly production.

To address the second issue, real-time efficiencies of the input resources to the output resources or of the input capital to the output capital in terms of market change needs to be recorded and will be used to make a decision on production adjustment facing varied market status. Substantial efforts had been made to describe those relationships among resources, surrounds, economy and society in recent decades. Investigation of Roelich K. et al. showed that some regulation means such as the communication technologies, the service levels and interconnectedness of infrastructure systems could have decreased levels of resource use effectively [11]. Investigation of Yakimchuk S.V. showed that human capital development would have played a regulatory role and would have become gradually an important factor in his investigated regions and that would have formed a new intellectual economy in the future [12]. Investigation of Warwick P.D. showed that unconventional natural resources such as coal bed methane, gas shale and shale oil had been becoming a substitute product and a necessary supplement for the conventional natural resources in our daily production and life [13]. These evidences showed that new technologies and new wisdoms would have improved primary development surroundings of the natural resources and that unconventional resource also would have turned to become a realtime adjustment mean as an essential alternatives in the entire economic system. However, all these efforts merely can do qualitative analysis on how the adjustment way may be done, which also cannot substantially solve the second issue or which can simply provide quantitative correlation with a certain regulatory mode. Thus, this distance is still far to solve authentically the real-time adjustment problem in efficiency.

A process evaluation parameter, a derived parameter stemmed from natural gas hydrate preparation from a small scale to an industrialization scale, will provide a possibility and an effective road to help us solve above two kinds of issues [14]. Thus, herein the parameter will be introduced in detail from its characteristics to its applications and 
the fundamental criterions will be provided for those judgments and those decisions before and during the economic activities in this work. Finally, the parameter and the criterions will be used to investigate process economics of natural resource utilization by introducing instances, which will provide some specific references for the diversified cases of natural resources utilization.

\section{Process Economics Criterion}

An economics process is assumed to become a thermodynamics process in this paper, thus thermodynamics viewpoints will be applied to characteristic investigation of the process evaluation parameter abovementioned and of the criterion of process economics.

\subsection{Process Evaluation Parameter}

Process evaluation parameter $\Omega$ rooted in natural gas hydrate storage and transportation technology not only was used to evaluate industrial processes from a small scale to industrialization scale and also was given a wider range of implications [14]. Analysis reveals that the $\Omega$ parameter is a dimensionless quantity similar to a value signal of the input-output for the current investigation. A schematic diagram of a virtual process system and a more extensive definition in terms of the process efficiency in economy is provided in more detail. Schematic diagram is shown in Figure1 and the expression of the parameter is written in Equation (1).

$$
\Omega=\frac{V_{i}}{V_{O}}
$$

where $\Omega$ is the process evaluation parameter for the systems and $V_{i}$ and $V_{O}$ are the resource inputs and outputs or the capital inputs and outputs, respectively.

Herein the virtual process in Figure 1 is assumed to become a serial of impending or ongoing affairs within a virtual black box frame including the resource activities with a constant mass composition. $V_{i}$ and $V_{O}$ can be generally replaced by the monetary value of the input and output resources or by the capital inputs and the capital outputs associated to the external market. The parameter is a function between internal activities of the model in Figure 1 and external market value movement, which bridges defects between internal resource amount change or internal resource movement of an actual process system and an external varied market factors in a certain time.

Alternatively, analyses also show that the process evaluation parameters significantly affect not only the aforementioned undeveloped and a developing resource excavation, but also the existing resource utilization in financial terms. The parameter can be divided into two halves for analysis: dynamic resources with practical monetary value and steady resources with potential value at a time point. The process evaluation parameter is a ratio

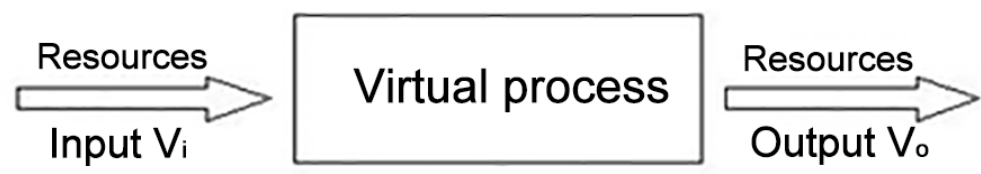

Figure 1. Schematic diagram of a virtual process system. 
of these two sub-parameters. For steady or undeveloped resources, the identification of the most appropriate development pathway often needs to be discussed. However, accurate investment should also be fully considered for dynamic resources or capital. By observing different process evaluation parameters in the economy, the capital could be identified for the best investment choice, including the resource application, to avoid risk [15] [16]. If these functions of the process evaluation parameter are considered as predictive properties, they can serve as a practical property, which indicates that the process evaluation parameter will continue to decrease due to the effect of science and technology advancements on the process evaluation parameter for a specific and social production process in the long run. With the progress of the production process or use of new technology, process improvements and management enhancements will decrease the value of the process evaluation parameter. In other words, it is a practical function that describes the decrease in the parameter. Generally, the process evaluation parameter should be compared with other parameters of a similar process in social production and an optimization of the parameter should be done subsequently, whose value will become a base to further process design and to form a plant. However, how can those functions of the process evaluation parameter be exerted in different time during the production period when capital is being fed to the developing resources continuously to yield a required product and how can the terminal of the developing process be identified? All these problems also will be able to be answered in terms of the expression in Equation (1) and will be considered as a practical property synchronously. Here the equation will be regarded as an efficiency in economics in any specified time before and during the period of the natural resource utilization. Generally, the value of the process evaluation parameter will fluctuate up and down around the initial set value and will be adjusted to controlled area by designed redundancy and by market regulation mode. Once all these adjusted methods cannot overcome the pressure from the external market or the efficiency in economics is too low to gain profitability, the time point can be considered to become a terminal for the resource utilization. Although the parameter has predictive properties and practical properties in natural resource utilization and in capital utilization, we are more concerned about how the process direction is determined and how the driving force is in science. Therefore, the criterions of the process movement and the size of the driving force will be elaborated in next sub-section.

\subsection{Expression of Criterion}

The process evaluation parameter is a function of the level of science and technology advancement and resource consumption [14]. This relationship is written as follows:

$$
\Omega=f(S T, R C)
$$

where $S T$ and $R C$ denote the level of science and technology advancement and resource consumption and $f$ is an arbitrary function.

The Equation shows that the process evaluation parameter can be mathematically expressed in the form of equations that can be solved according to the state of scientific 
advancement, resource conditions, etc.

Research indicates that the process evaluation parameter is a function of similar characteristics with a state function of thermodynamics [17]. Each numerical value of the parameter represents a state with a certain level of science and technology advance and resource consumption and has implications of the process efficiency in economy or of the process efficiency of resource utilization. The theories of those thermodynamic process and the principles of capital economics will become thought sources of the criterions of the process economics. Mathematical expression of the criterion is represented to become a difference between the value of the process evaluation parameter at the final state and the value of the process evaluation parameter at the initial state in an actual process, which can be written as

$$
\Delta \Omega=\Omega_{f}-\Omega_{i}
$$

where $\Delta \Omega, \Omega_{f}$ and $\Omega_{i}$ are the change in the value of the process evaluation parameter between different states, the value of the process evaluation parameter at the final state and the value of the process evaluation parameter at the initial state.

The difference in Equation (3) represents the size of the driving force of the actual process of the resource utilization and thus the equation can become a criterion of the process economics. Using the equation the direction of development can be determined and the size of the driving force also can be judged simultaneously in an actual production process or a run in economics.

If $\Delta \Omega$ is less than zero, then it means that the production efficiency in economy or process efficiency of resource utilization at the final state is higher than that at the initial state. Thus, the process change is promising. In other words, this condition results in a driving force from an initial state to a final state; the process will continue to change from the levels of science and technology advancement or the conditions of resources consumption. The process change positively correlates with the value of the process evaluation parameter and also with the amplitude of value's variation of the process evaluation parameter.

If $\Delta \Omega$ equals zero, then it means that the production efficiency in economy at the final state is equal to that at the initial state. Thus, the process does not need to be changed. In other words, the initial and final process efficiencies of resource utilization are equal. If $\Omega_{i}$ and $\Omega_{f}$ are simultaneously equal to the average value of the process evaluation parameter of the entire society, then the production process at the final state cannot be improved from the levels of science and technology advancement or the conditions of resources consumption. It can merely be reproduced simply at a same level of social production.

If $\Delta \Omega$ is more than zero, the initial process is better than the final process. In other words, the production efficiency in economy or process efficiency of resource utilization at the initial state excels that at the final state. At this condition, the process cannot proceed spontaneously from the initial state to the final state in perfect competition market. In other words, an adverse direction is possible from the point of view of process efficiency in economy. Furthermore, the final process will be eliminated in social production because of lower efficiency of resource utilization or capital use. 
However, if $\Omega_{i}$ is infinite and $\Omega_{f}$ is a constant for the development of the process, then $\Delta \Omega$ will equal negative infinity. These values indicate that a significant amount of time will be consumed from an impossible process and to an available process by data analysis. If $\Omega_{i}$ is a constant and $\Omega_{f}$ is infinite for the development of the process, then $\Delta \Omega$ is positive infinity, which indicates that the operating process will gradually lose its position and eventually disappear in social production because of almost no outputs from the variable tendency.

These criterions indicate that the process evaluation parameter change in value or the parameter itself can help to identify the direction of an actual process and help to make a strategic decision to process selection or economic adjustment in social production.

\section{Application of the Parameter and of the Criterion}

In order to solve the first issue and the second issue abovementioned use of the parameter and of the criterions with regard to process economics will be illustrated in this section. Because the selection of a process and a real-time adjustment are still quite complicated to effectively utilize a natural resource, diversified considerations requires to be done. The key is an identification of the optimal use or the adjustable use mean of the natural resources in them. Concrete examples will be introduced in terms of the aforementioned principles to identify the best utilization and a real-time adjustment mean of the natural resources [18].

\subsection{Use for Undeveloped Resources}

For undeveloped resources, the resource consumption is zero; thus, the process evaluation parameter $\Omega$ will vary according to the following Equation

$$
\Omega=f(S T)
$$

where ST denotes the level of science and technology advancement and $\mathrm{f}$ is an arbitrary function.

In other words, the process evaluation parameter is merely related to the level of the natural and social sciences. The following examples indicate methods to select the processes to maximize the use of natural resources, such as coal, oil, natural gas, natural gas hydrate, uranium mine, and iron ore. The utilitarian values of the criterion will be revealed by analyzing all kinds of choices of development scheme of following several common circumstances in terms of their levels of current science and technology.

\subsubsection{No Developed Technology}

Suppose a deposit of natural gas hydrate is found in a seabed, and the development objective is to obtain methane fuel [19]. However, the technology for industrial production is not currently available. Under this condition the value of the process evaluation parameter at this initial state $\Omega_{i}$ is infinite. If a constant value of the parameter for the final state $\Omega_{f}$ is assumed while natural gas hydrate can be exploited with a higher efficiency in economy. Then, the change in value of the process evaluation parameter $\Delta \Omega$ approaches negative infinity at this condition, which is represented as follows 


$$
\Delta \Omega=\Omega_{f}-\Omega_{i}=-\infty
$$

Thus, the process can proceed according to the assumed conditions. However, the development of practical technology for the exploration of natural gas hydrates is still in its infancy. In other words, it needs to consume a significant amount of time that the process evaluation parameter $\Omega_{f}$ at the final state become a constant. Furthermore, this development also requires many tests [20]. The selection of processes for a given resource can only be discussed after the process matures. If we assume that natural resources, such as natural cold energy, water power, solar energy, and wind energy, have zero cost in terms of the process evaluation parameter, then natural cold energy [21] or artificial cold energy converted from renewable energy, wind energy, or solar energy [22] [23] [24] [25] by electric energy as a transitional energy can be stored as natural gas hydrate. At that time the process evaluation parameter is smaller than for other conditions with resource costs. The parameter value is therefore helpful to overcome the economic hurdle posed by the inability of natural gas hydrate storage and transportation technology to compete with pipeline natural gas transportation and liquefied natural gas transportation from a theory [26] [27] [28]. However, if we approach this problem from the perspective of the practical function of the process evaluation parameter, then natural gas hydrate cannot be currently used as an economic storage and transportation for natural gas, and process improvements and process management enhancements still are necessary. It still will consume a lot of time that the process turns competitive. Therefore, a process is not currently from those analyses of the process evaluation parameter and the process evaluation criterion.

\subsubsection{A Single Option for Developed Technology}

If iron ore is found, the corresponding development goal is the use of its ferrum. The following steps can be performed for this analysis. First, the current market values and ultimate minable resource mass are estimated based on the ore grade. Second, the investment is calculated and an appropriate production model is selected according to the order of results to compare the process evaluation parameter of the different runs of iron and steel enterprises with the help of the above principles. At this time point the minimal value of the process evaluation parameter in them, $\Omega_{\min }$ is assumed. Afterwards, the value will become a primary value designed at the initial state in the future resource development. Moreover, capital states, the future market demand, the behavior of investors, national economic models, etc., must still be considered [29], after which the use of resources as raw materials or materials in a new plant should be decided. Only after the analysis and study are completed for the aforementioned process, can the optimal resource allocation and the best economic values be identified. After the decision on setting up a new plant is made, the selected value of the process evaluation parameter, $\Omega o$, is written as $\Omega_{0}$ and the time is written as $\mathrm{t}_{0}$. Here the parameter, $\Omega o$ may be same as $\Omega_{\min }$ and also may be equal to revised $\Omega_{\min }$ after other factors is considered into the designed state. Moreover, the value of the process evaluation parameter at the initial time and the initial time are assumed to be $\Omega_{1}$ and $t_{1}$ when the iron ore resource just begins to be utilized. With the progress of the time, the iron ore re- 
sources will proceed from $t_{0}$ to $t_{1}$ in term of designed way until the designed results of the iron ore resources is accomplished, whose process is considered as a non-spontaneous process under the support of the selected technology with a large driving force from the external capital or the external resource. The change is described as following Equation:

$$
\Delta \Omega_{1}=\Omega_{1}-\Omega_{0}=+\infty
$$

In other words, the change in value of the process evaluation parameter $\Delta \Omega_{1}$ approaches positive infinity in terms of the abovementioned principle and of the parameter's definition because $\Omega_{0}$ and $\Omega_{1}$ are a constant and infinity respectively. Once investment project is completed, the constructed process also ends.

In conclusion, the process evaluation parameter itself and the change in value of the process evaluation parameter can judge the direction of the process and the ongoing extent of the process clearly facing single option of the resource utilization mode.

\subsubsection{A Number of Options for Developed Technology}

The development goal is to use the coal resources if a coal mine is found. Because of the multidimensionality of the development objectives, such as coal combustion heating, coal gasification for clean fuel, coal liquefaction for oil substitute, and coal carbonization, the factors in the processes selection for the application of resources are complicated [10]. The following steps can generally be performed when considering these conditions. First, the current market values based on the coal quality and ultimate minable resource mass are estimated. Second, the developing routes are assessed. Third, suitable paths with the best process evaluation parameters in the different developing routes are selected according to steps cited for only a single option for developed tech-

nology. Fourth, the selected process evaluation parameters are compared, and the optimal process evaluation parameters, $\Omega_{O}$, are identified. Finally, certain concepts from having only a single developed technology are referenced to optimize the coal resource allocation.

Suppose that the utilization options only include the above four routes for the coal under perfect competition conditions [30]. In this situation, the best utilization of resources needs to be determined. The following steps lay out a specific process for selecting the optimal coal utilization.

1) Process Selection Analysis for Development Path

a) Coal Combustion Heating

First, the heat efficiencies of different coal combustion processes in industry are compared, and the process evaluation parameter values are given and ranked. Second, the appropriate process evaluation parameter, $\Omega_{1}$, is selected. Finally, the coal combustion process and devices are determined.

b) Coal Gasification for Clean Fuel

The process evaluation parameters for different coal gasification processes in industry are compared and ranked, and the appropriate process evaluation parameters, $\Omega_{2}$, are given. Next, the coal gasification process and devices are determined.

c) Coal Liquefaction for Oil Substitute 
At present, the technology is limited to the small-scale and scaled-up experimental plant. Industrialized experiments must be processed. Therefore, the process evaluation parameter values, $\Omega_{3}$, are generally greater, and the experimental processes cannot be used to produce an oil substitute that is more competitive in the market.

d) Coal Carbonization

The process evaluation parameters are compared for the different coal carbonization processes in industry, and the appropriate process evaluation parameter, $\Omega_{4}$, is given. Afterwards, the coal carbonization process and devices are determined.

2) Processes Comparison and Selection

The above resource utilization processes are compared, and the optimal process evaluation parameter, $\Omega_{0}$, is selected. Generally, the smallest process evaluation parameter, $\Omega_{\min }$, is the best choice under perfect competition after other factors mentioned in last sub-section is considered adequately. That is,

$$
\Omega_{O}=\Omega_{\min }
$$

where $\Omega_{O}$ and $\Omega_{\min }$ denote the optimal process evaluation parameter and the smallest process evaluation parameter, respectively.

Several concepts for the case of having only a single developed technology are referenced to optimize the coal resource allocation under the condition of a market economy [31] [32].

In conclusion, the change in value of the process evaluation parameter, $\Delta \Omega$, still approaches positive infinity. The size of the driving force or change of the parameter value still can become a criterion to guide the direction and the extent of the actual process.

\subsection{Use for a Developing Resource}

After a road of resources utilization is identified, use of the undeveloped resource will be put on the agenda. However, how the use adjustment of developing natural resources should do still is worth to be considered carefully. Comparative investigation of Uris M. et al. showed that limited natural resource should be provided to those units with a higher profitability in the allocation of biomass resources in terms of size of the plant, annual operation hours and price of biomass after the techno-economic feasibility assessment had been completed [33]. Gori F. used actual data from the market report to acquire model parameters of the mass and energy-capital conservations and the mathematical model equation was used to forecasts monthly price in a closed system when an oil field was being mined [34]. These investigations related to developing resources can help us make adjustments on the market allocations of the entire resources and can help us make investment risk prediction of the resources with a forward-looking view. But these works also merely can do qualitative analysis for the developing resources and cannot give a solution quantitatively. In other words, they cannot reveal the substantive relationship of the real-time adjustment among resources, market and adjustment means for the system of the developing resource. Since the process evaluation parameter $\Omega$ has its own resource attributes and its own social attributes and plays a multiple roles in prediction and in practice, it also can guide a real-time adjustment of developing resources. 
When the developing resources are used, the process evaluation parameter $\Omega$ will vary according to the following Equation

$$
\Omega=f(R C)
$$

Now we should consider the internal resource status using black box model abovementioned. Assume total resources amount in a mineral deposit are $M_{0}$ and $M(t)$ when resource development time are 0 and $t$, respectively. Then the value of the process evaluation parameter $\Omega(\mathrm{t})$ at any time can be represented to become

$$
\Delta \Omega=\frac{\beta(t) P_{i 0}}{G_{0} \frac{[\exp (\alpha t)-1]}{\alpha} P_{M}(t)}-C
$$

where $\mathrm{P}_{\mathrm{M}}(\mathrm{t}), P_{10}$ and $\beta(\mathrm{t})$ are a product market value in any time, an initial input value designed for undeveloped resource and a market dynamic adjustment function with any time for a different exploitation difficulty.

Here Equation (9) is called as a process economics model of the natural resource utilization. From the viewpoint of the model equation we can know that the relationship between the internal resource change and external markets of resource development has been established.

Based on reference [34], total petroleum resource amount in a reservoir in any time can be written as

$$
M(t)=M_{0}+G_{0} \frac{[1-\exp (\alpha t)]}{\alpha}
$$

where $G_{0}$ and $\alpha$ are an initial extraction mass flow rate and an extraction rate.

If Equation (10) is substituted to Equation (9), then the process evaluation parameter $\Omega(t)$ becomes

$$
\Omega(t)=\frac{\beta(t) P_{i 0}}{G_{0} \frac{[\exp (\alpha t)-1]}{\alpha} P_{M}(t)}
$$

where $\Omega(\mathrm{t}), \mathrm{P}_{\mathrm{M}}(\mathrm{t}), P_{i 0}, \beta(\mathrm{t}), \mathrm{G}_{0}$ and $\alpha$ are the value of the process evaluation parameter at any time, a product market value in any time, an initial input value designed for undeveloped resource and a market dynamic adjustment function with any time for a different exploitation difficulty, an initial extraction mass flow rate and an extraction rate, respectively.

The equation reflects a ratio between input monetary value and output monetary value at any time during a petroleum exploitation, which includes resource development status and external market conditions. From Equation (11) we can see that internal petroleum resource exploitation in a black box and external dynamic market are related by the process evaluation parameter at any time.

The parameter value can be used to evaluate capital efficiency status in petroleum resource exploitation itself at any time neglecting the time lag at a real-time control and to compare with the parameter value at initial state and with other petroleum resource 
development status in a market economics model, and finally to make an appropriate decision for a dynamic production real-time adjustment such as improving production rate or reducing production rate.

Although the value of the process evaluation parameter at any time has a certain effect on assessing real-time capital efficiency in the petroleum resource exploitation, here we are still concerned about how to drive the resource exploitation between different states or how the power of resource exploitation is. Thus, the size of the driving force or the change in the value of the process evaluation parameter between different states still needs to be calculated and can be written as

$$
\Delta \Omega=\Omega_{f}-\Omega_{i}=\Omega(t)-\Omega_{i}
$$

where $\Delta \Omega, \Omega_{f} \Omega_{i}$ and $\Omega(t)$, are the change in the value of the process evaluation parameter between different states, the value of the process evaluation parameter at the final state, the value of the process evaluation parameter at the initial state and the value of the process evaluation parameter at any time, respectively.

Because the value of the process evaluation parameter at the initial state is a constant selected from the designer of the process, here it is assumed as a constant value $C$. Substitute Equation (11) and the value of the process evaluation parameter at the initial state into Equation (12), the change in the value of the process evaluation parameter from the initial state to the final state becomes

$$
\Omega=\frac{\beta(t) P_{i 0}}{G_{0} \frac{[\exp (\alpha t)-1]}{\alpha} P_{M}(t)}-C
$$

where $\Delta \Omega, P_{M}(t), P_{i 0}, \beta(\mathrm{t}), G_{0}, \alpha$ and $\mathrm{C}$ are the change in the value of the process evaluation parameter between different states, a product market price in any time, an initial input value designed for undeveloped resource and a market dynamic adjustment function with any time for a different exploitation difficulty, an initial extraction mass flow rate, an extraction rate, and a constant, respectively.

The change value of the process evaluation parameter in Equation (13) indicates the difference between the capital efficiency status in petroleum at a time and the capital efficiency status in petroleum at the designed time of the initial state. The difference can be shown in Figure 2 after the effect of the time lag is neglected under the stable market of perfect competition.

Figure 2 indicates that the value of the process evaluation parameter at any time fluctuates with the value of the process evaluation parameter selected at the initial state from 0 to the twelfth years and will increases to infinity with the increase of the exploitation difficulty of the petroleum resource. On the one hand, under the exploitation difficulty designed of the petroleum resource the function value of the process evaluation parameter at any time is adjusted in real-time to the set value by process improvements and management. On the other hand, the function value of the process evaluation parameter at any time turns bigger and bigger until infinity because the exploitation difficulty of the petroleum resource increases and the current technology has not been able to 


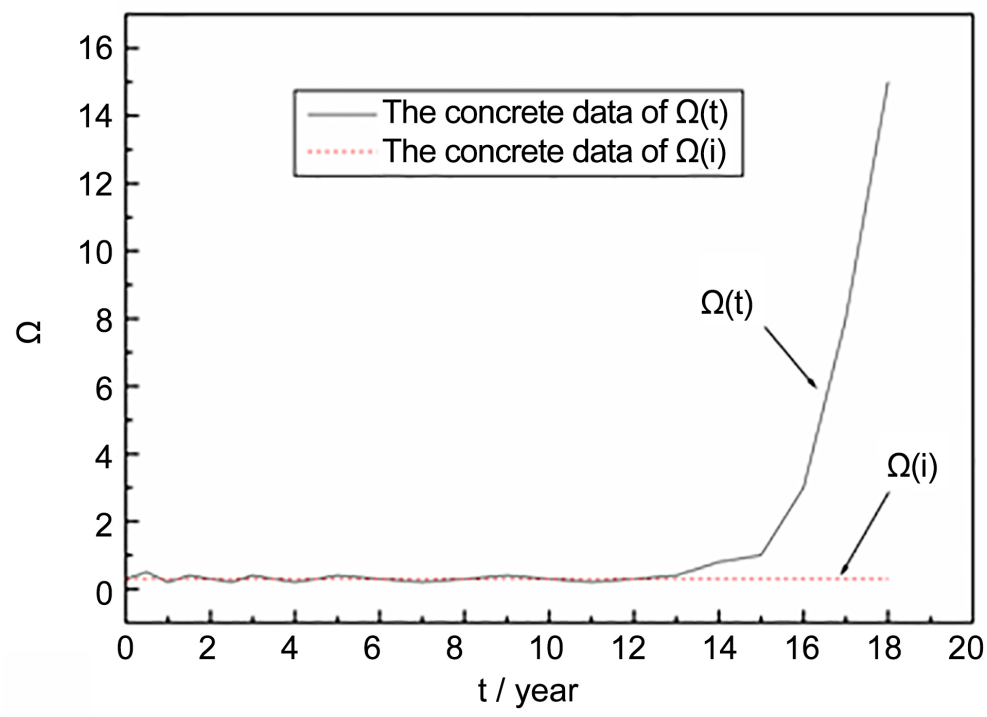

Figure 2. Schematic diagram of the value of the process evaluation parameter at any time and of the value of the process evaluation parameter at the initial state.

adjust the parameter to controllable area to face market competition. Thus, a new process evaluation with a new technology such as the secondary oil recovery and tertiary oil recovery must be done to complete the next identification of the value of the process evaluation parameter from social production or scientific experiment under this condition.

\subsection{Applied Analysis}

The parameter and the criterion are not only proposed themselves in theory, but they can also be served to some assignments in practice. The parameter and the criterion include the natural and social attributes of natural resource utilization, as well as a dual predictive roles for future resource exploration or capital utilization and multiple practical roles whether before resources utilization and capital use or during resources utilization and capital use. Whether considering resource extraction or capital utilization, the most basic function of the parameter and of the criterion are the appraisal of the processes, the identification of levels and determination of driving force of the process, which will become an important basis and provide significant information for the development of resources and the venture forecasting of capital utilization [35] [36]. Moreover, the parameter and the criterion are predictive and practical for the development direction of the process and can thus serve to guide the direction of scientific research and engineering practice, such as the development of renewable energy storage technology for the storage of natural gas hydrate and the adjustment of the present preparation methods or improvements of comprehensive levels of natural gas hydrate.

\section{Conclusions}

The process evaluation parameter defined by the development processes of natural gas 
hydrate synthesis technology and the formative kinetic criterions of the identification of process direction can guide the direction of general scientific development and make a decision for dynamic production adjustment during resource utilization processes. From the analyses and the applications of the parameter and of the criterion of the process evaluation, the following conclusions can be drawn:

1) The parameter analyses indicate that the process evaluation parameter is relevant to internal undeveloped resources amount in a virtual black box model and external market. Moreover, the parameter has implications of process efficiency in economy or of process efficiency of resource utilization and has similar features of the thermodynamic state functions.

2) The equation of the criterion is a difference between the value of the process evaluation parameter at the final state and the value of the process evaluation parameter at the initial state in an actual process, which can be used to determine the direction of development and to judge the size of the driving force in an actual production process or a run in economy.

3) The use examples of the parameter itself and of the criterion of the process evaluation can guide how an identification of the process implemented in multiple options for the undeveloped resources and of a real-time adjustment mean of dynamic production for the developing resource should be done and how a decision regarding resource exploitation and the venture forecasting of capital utilization should be made before the exploitation of the natural resources and during the exploitation of the natural resources.

4) Process efficiency of natural resource utilization or capital efficiency in economy can be described by the value of the process evaluation parameter. The process evaluation parameter can be drawn to become a variable curve with a time, which fluctuates with the process evaluation parameter selected at the initial state under the market condition of perfect competition. The point of inflection for the curve will have possibility to become a symbol of the updating technology.

5) The parameter itself and the criterion of the process evaluation can help by playing a predictive role for selecting the optimal use processes and for designing new process of the natural resource utilization or capital use, and by playing a practical role for adjusting factual production status and for improving the actual process of the utilization of resource or capital in an economic society.

6) The investigated results are applicable to those closed resource systems without accumulation or depletion of the resources whose effective compositions always keep a constant, except for those systems with a variable mass such as a decomposition system, a fission system and a biological reproduction system.

\section{Acknowledgements}

The financial support from the Chinese Natural Science Foundation (No. 50176051, 090410003 and 20490207), the Natural Science Foundation of Liaoning Province (No. 2013020150) and the Program for Liaoning Excellent Talents in University (No. LJQ2011134) are gratefully acknowledged. 


\section{References}

[1] Kaye, L.K., Wall, H.J. and Malone, S.A. (2016) Turn That Frown Upside-Down: A Contextual Account of Emoticon Usage on Different Virtual Platforms. Computers in Human Behavior, 60, 463-467. http://dx.doi.org/10.1016/j.chb.2016.02.088

[2] Chen, H., Yang, X., Chen, L., Wang, Y. and Sun, Y. (2016) Application of FDM ThreeDimensional Printing Technology in the Digital Manufacture of Custom Edentulous Mandible Trays. Scientific Reports, 6, Article Number: 19207. http://dx.doi.org/10.1038/srep19207

[3] American Association of Petroleum Geologists, Energy Minerals Division (2015) Unconventional Energy Resources: 2015 Review. Natural Resources Research, 24, 443-508. http://dx.doi.org/10.1007/s11053-015-9288-6

[4] Rowe, A. (2012) Evaluation of Natural Resource Interventions (Review). American Journal of Evaluation, 33, 384-394. http://dx.doi.org/10.1177/1098214012440026

[5] Gevorkyan, A. and Semmler, W. (2016) Oil Price, Overleveraging and Shakeout in the Shale Energy Sector-Game Changers in the Oil Industry. Economic Modelling, 54, 244-259. http://dx.doi.org/10.1016/j.econmod.2015.12.029

[6] Schlör, H., Fischer, W. and Hake, J.F. (2012) The Meaning of Energy Systems for the Genesis of the Concept of Sustainable Development. Applied Energy, 97, 192-200. http://dx.doi.org/10.1016/j.apenergy.2012.03.009

[7] Kucukvar, M. and Tatari, O. (2011) A Comprehensive Life Cycle Analysis of Cofiring Algae in a Coal Power Plant as a Solution for Achieving Sustainable Energy. Energy, 36, 65326537. http://dx.doi.org/10.1016/j.energy.2011.09.039

[8] Parker, P. and Thapa, B. (2012) Natural Resource Dependency and Decentralized Conservation within Kanchenjunga Conservation Area Project, Nepalv. Environmental Management, 49, 435-444. http://dx.doi.org/10.1007/s00267-011-9791-4

[9] Yuasa, K., Park, S.J. and Fujii, S. (2012) Energy Conservation Assessment of District Heating and Cooling System Based on Life-Cycle Energy. Journal of Environmental Engineering, 77, 507-513. http://dx.doi.org/10.3130/aije.77.507

[10] Ma, Y.F., Yuan, Y.C, Jin, J., Zhang, H., Hu, X.H. and Shi, D.Y. (2013) An Environment Friendly and Efficient Lignite-Fired Power Generation Process Based on a Boiler with an Open Pulverizing System and the Recovery of Water from Mill-Exhaust. Energy, 59, 105115. http://dx.doi.org/10.1016/j.energy.2013.06.073

[11] Roelich, K., Knoeri, C., Steinnerger, J.K., Varga, L., Blythe, P.T., Butler, D., Gupta, R., Harrison, G.P., Martin, C. and Purnell P. (2015) Towards Resource-Efficient and ServiceOriented Integrated Infrastructure Operation. Technological Forecasting and Social Change, 92, 40-52. http://dx.doi.org/10.1016/j.techfore.2014.11.008

[12] Yakimchuk, S.V. (2015) Human Capital Development: The Regional Aspect. Economic Annals- XXI, 1-2, 20-23.

[13] Warwick, P.D. (2011) Unconventional Energy Resources: 2011 Review. Natural Resources Research, 20, 279-328. http://dx.doi.org/10.1007/s11053-011-9157-x

[14] Hao, W.F., Wang, J.Q., Fan, S.S. and Hao W.B. (2008) Evaluation and Analysis Method for Natural Gas Hydrate Storage and Transportation Processes. Energy Conversion and Management, 49, 2546-2553. http://dx.doi.org/10.1016/j.enconman.2008.05.016

[15] Aven, T. (2009) Perspectives on Risk in a Decision-Making Context-Review and Discussion. Safety Science, 47, 798-806. http://dx.doi.org/10.1016/j.ssci.2008.10.008

[16] Crona, B.I. and Parker, J.N. (2012) Learning in Support of Governance: Theories, Methods, 
and a Framework to Assess How Bridging Organizations Contribute to Adaptive Resource Governance. Ecology and Society, 17, 32. http://dx.doi.org/10.5751/ES-04534-170132

[17] Boles, M.A. and Cengel, Y. (2010) Thermodynamics: An Engineering Approach. 7th Edition, McGraw-Hill Education, New York.

[18] Walsh, M.R., Hancock, S.H., Wilson, S.J., Patil, S.L., Moridis, G.J., Boswell, R., Collett, T.S., Koh, C.A. and Sloan, E.D. (2009) Preliminary Report on the Commercial Viability of Gas Production from Natural Gas Hydrates. Energy Economics, 31, 815-823. http://dx.doi.org/10.1016/j.eneco.2009.03.006

[19] Koh, C.A., Sum, A.K. and Sloan, E.D. (2012) State of the Art: Natural Gas Hydrates as a Natural Resource. Journal of Natural Gas Science and Engineering, 8, 132-138. http://dx.doi.org/10.1016/j.jngse.2012.01.005

[20] Konno, Y., Oyama, H., Nagao, J., Masuda, Y. and Kurihara, M. (2010) Numerical Analysis of the Dissociation Experiment of Naturally Occurring Gas Hydrate in Sediment Cores Obtained at the Eastern Nankai Trough, Japan. Energy and Fuels, 24, 6353-6358. http://dx.doi.org/10.1021/ef1008727

[21] Yang, T., Zhang, X., Zhou, B. and Zheng, M. (2013) Simulation and Experimental Validation of Soil Cool Storage with Seasonal Natural Energy. Energy and Buildings, 63, 98-107. http://dx.doi.org/10.1016/j.enbuild.2013.03.019

[22] Kélouwani, S., Agbossou, K. and Chahine, R. (2005) Model for Energy Conversion in Renewable Energy System with Hydrogen Storage. Journal of Power Sources, 140, 392-399. http://dx.doi.org/10.1016/j.jpowsour.2004.08.019

[23] Tian, Y. and Zhao, C.Y. (2013) A Review of Solar Collectors and Thermal Energy Storage in Solar Thermal Applications. Applied Energy, 104, 538-553. http://dx.doi.org/10.1016/j.apenergy.2012.11.051

[24] Benitez, L.E., Benitez, P.C. and van Kooten, G.C. (2008) The Economics of Wind Power with Energy Storage. Energy Economics, 30, 1973-1989. http://dx.doi.org/10.1016/j.eneco.2007.01.017

[25] Sioshansi, R. (2011) Increasing the Value of Wind with Energy Storage. Energy Journal, 32, 1-30. http://dx.doi.org/10.5547/ISSN0195-6574-EJ-Vol32-No2-1

[26] Najibi, H., Rezaei, R., Javanmardi, J., Nasrifar, K. and Moshfeghian, M. (2009) Economic Evaluation of Natural Gas Transportation from Iran's South-Pars Gas Field to Market. Applied Thermal Engineering, 29, 2009-2015. http://dx.doi.org/10.1016/j.applthermaleng.2008.10.008

[27] Lochner, S. (2011) Identification of Congestion and Valuation of Transport Infrastructures in the European Natural Gas Market. Energy, 36, 2483-2492. http://dx.doi.org/10.1016/j.energy.2011.01.040

[28] Lee, S., Seo, Y., Lee, J. and Chang D. (2016) Economic Evaluation of Pressurized LNG Supply Chain. Journal of Natural Gas Science and Engineering, 33, 405-418. http://dx.doi.org/10.1016/j.jngse.2016.05.039

[29] Booker, J.F., Howitt, R.E., Michelsen, A.M. and Young, R.A. (2012) Economics and the Modeling of Water Resources and Policies. Natural Resource Modeling, 25, 168-218. http://dx.doi.org/10.1111/j.1939-7445.2011.00105.x

[30] McAllister, R.R.J., Tisdell, J.G., Reeson, A.F. and Gordon, I.J. (2011) Economic Behavior in the Face of Resource Variability and Uncertainty. Ecology and Society, 16, 6. http://dx.doi.org/10.5751/ES-04075-160306

[31] Altman, M. (2012) Implications of Behavioural Economics for Financial Literacy and Public Policy. Journal of Socio-Economics, 41, 677-690. 
http://dx.doi.org/10.1016/j.socec.2012.06.002

[32] Aplak, H.S. and Sogut, M.Z. (2013) Game Theory Approach in Decisional Process of Energy Management for Industrial Sector. Energy Conversion and Management, 74, 70-80. http://dx.doi.org/10.1016/j.enconman.2013.03.027

[33] Uris, M., Linares, J.I. and Arenas, E. (2014) Techno-Economic Feasibility Assessment of a Biomass Cogeneration Plant Based on an Organic Rankine Cycle. Renewable Energy, 66, 707-713. http://dx.doi.org/10.1016/j.renene.2014.01.022

[34] Gori, F. (2013) Mass and Energy-Capital Conservation Equations to Forecast Monthly Oil Price. Applied Thermal Engineering, 61, 623-632. http://dx.doi.org/10.1016/j.applthermaleng.2013.08.031

[35] Ghaseminejad, A.H. (2013) Society, Technology, Product, and Responsibility: A Dynamic Feedback Systems Perspective. International Journal of Technology, Knowledge and Society, 9, 225-241.

[36] Todd, P.R., Javalgi, R.G. and Grossman, D. (2014) Understanding the Characteristics of the Growth of SMEs in B-to-B Markets in Emerging Economies: An Organizational Ecology Approach. Journal of Business and Industrial Marketing, 29, 295-303. http://dx.doi.org/10.1108/JBIM-08-2013-0189

\section{Nomenclature}

\begin{tabular}{|c|c|c|}
\hline \multicolumn{3}{|r|}{ General symbols } \\
\hline$C$ & {$[-]$} & A constant \\
\hline$f$ & {$[-]$} & Function \\
\hline$G$ & {$\left[\mathrm{~kg} \cdot\right.$ annum $\left.^{-1}\right]$} & Mass flow rate of extraction for undeveloped resources \\
\hline$M$ & {$[\mathrm{~kg}]$} & Mass \\
\hline$P$ & $\begin{array}{c}\left.\text { [dollar } \cdot \mathrm{kg}^{-1}\right] \\
\text { [dollar] }\end{array}$ & Product market priceper unit or Input value for a product \\
\hline$R C$ & {$[-]$} & Resource consumption \\
\hline$S T$ & {$[-]$} & Science and Technology \\
\hline$t$ & {$[\mathrm{~s}]$} & Time \\
\hline$V$ & [dollar] $[\mathrm{kg}]$ & Resources utilization or mass \\
\hline \multicolumn{3}{|r|}{ Special characters } \\
\hline$\alpha$ & {$\left[\% \cdot\right.$ annum $\left.^{-1}\right]$} & Resource extraction rate \\
\hline$\beta$ & {$[-]$} & Resource exploitation difficulty function \\
\hline$\Delta$ & {$[-]$} & Change value of a parameter \\
\hline$\Omega$ & {$[-]$} & A parameter of process evaluation \\
\hline \multicolumn{3}{|r|}{ Subscripts } \\
\hline 1,2 & & State point \\
\hline 3,4 & & State point \\
\hline$i, f$ & & Initial state and final state \\
\hline$i, o$ & & Input and output \\
\hline $\min$ & & Minimum value \\
\hline 0 & & Reference value or state point \\
\hline
\end{tabular}


Submit or recommend next manuscript to SCIRP and we will provide best service for you:

Accepting pre-submission inquiries through Email, Facebook, LinkedIn, Twitter, etc. A wide selection of journals (inclusive of 9 subjects, more than 200 journals)

Providing 24-hour high-quality service

User-friendly online submission system

Fair and swift peer-review system

Efficient typesetting and proofreading procedure

Display of the result of downloads and visits, as well as the number of cited articles

Maximum dissemination of your research work

Submit your manuscript at: http://papersubmission.scirp.org/

Or contact nr@scirp.org 